\title{
Adult Central Nervous System Germ Cell Tumor
}

National Cancer Institute

\section{Source}

National Cancer Institute. Adult Central Nervous System Germ Cell Tumor. NCI

Thesaurus. Code C6285.

A germ cell tumor of the central nervous system occurring in adults. 